\title{
O Bebê Imaginado e a Constituição das Identidades Materna, Paterna e do Bebê
}

\author{
Tatiele Jacques Bossi* \\ Universidade Federal do Rio Grande do Sul, Porto Alegre, RS, Brasil \\ Omar Ardans- \\ Universidade Federal de Santa Maria, Santa Maria, RS, Brasil
}

\begin{abstract}
RESUMO
O presente estudo investigou as expectativas parentais em relação ao bebê imaginado e suas influências na constituição da identidade materna, paterna e do bebê. Participaram do estudo três casais primigestos que responderam a entrevistas durante o $3^{\circ}$ trimestre gestacional. A análise de conteúdo qualitativa destacou as expectativas parentais relacionadas ao sexo, à escolha do nome e às características físicas e psicológicas do bebê imaginado. A nomeação do bebê, a partir das expectativas parentais, pareceu exercer influências na estruturação da identidade materna e paterna. Nesse sentido, ao nomearem o filho, os pais e mães já viam sua própria identidade sendo transformada. Da mesma forma atribuíam características identitárias ao bebê, permitindo-lhe ser sujeito na família antes de seu nascimento.
\end{abstract}

Palavras-chave: bebê imaginado; identidade materna e paterna; primeiro filho.

\begin{abstract}
The Imagined Baby and the Mother's, Father's and Baby's Identities Constitution

The present research has investigated the parents expectations about the imagined baby and their influences on mother's, father's and baby's identities constitution. Three couples pregnancy for the first time were interviewed during the third trimester of pregnancy. The qualitative content analysis has indicated the parents expectations related baby's sex, choice of the baby's name and his physical and psychological characteristics. It noticed that the parents expectations have influenced the mother's and father's identities constitution, at mean that the parents have changed their own identity through the baby mention. The same way, they have already attributed child's identity characteristics allowing $\mathrm{him} / \mathrm{her}$ to be subject in the family before him/her birth.
\end{abstract}

Keywords: imagined baby; mother's and father's identities; first child.

A gestação do primeiro filho é uma importante etapa na constituição da parentalidade, já que envolve a mudança de perspectiva de somente filho e casal, para uma perspectiva parental. Também é o momento em que inúmeras expectativas em relação ao filho se fazem presentes, o que intensifica a estruturação do bebê imaginado no psiquismo parental, o qual carrega as primeiras características de identidade atribuídas ao filho (Lebovici, 1987; Szejer \& Stewart, 1997/2002).

A identidade é uma produção social e cultural que tem sua estruturação pautada, principalmente, através de atos de linguagem (Ciampa, 1987/2001; Silva,
2000/2005). É através da nomeação que uma identidade é produzida sendo que, sem isso, dificilmente será estruturada e atribuída a alguém (Silva, 2000/ 2005). Esta nomeação pode existir antes mesmo do nascimento de um filho e estar baseada nas expectativas dos pais ${ }^{1}$ e mães em relação ao bebê imaginado. Tal fato já permite ao bebê ter sua identidade no ambiente familiar, da mesma forma que os pais e mães podem se atribuir uma identidade parental.

Nesse sentido, Golse (2002) destacou que as mães e pais carregam em sua mente quatro tipos de bebês: o fantasmático, o imaginário, o narcísico e o mítico. A 
criança fantasmática existe na mente materna e paterna separadamente, já que se relaciona com a história pessoal dos genitores, sendo formada com base nas representações inconscientes do pai e da mãe. Já a criança imaginária faz parte do psiquismo do casal, sendo, assim, menos inconsciente que o bebê fantasmático, e carrega as representações sobre como a criança será, em aspectos físicos (sexo, cor do cabelo, cor dos olhos) e psicológicos (será calmo, agitado, meigo). A criança narcísica é a representante do ideal de perfeição dos pais e mães, colocando aos filhos o atributo de serem mais bonitos que seus genitores, mais competentes, mais realizados em seus sonhos. E por fim, a criança mítica varia de acordo com cada contexto social e histórico, já que se refere às representações culturais atribuídas à infância. Esses bebês, segundo o autor, interagem no psiquismo materno e paterno influenciando a relação que será estabelecida entre mãe/pai-bebê.

Já para Lebovici (1987) a mãe (e pode-se pensar também o pai, embora menos ressaltado pelo autor) teria em seu psiquismo a formação de três bebês: o bebê edípico, o bebê imaginário e o bebê propriamente dito. O bebê edípico caracteriza-se por ser o mais inconsciente de todos, sendo resultado das experiências infantis maternas relativas ao complexo de Édipo e aos desejos infantis. Já o bebê imaginário seria constituído a partir da gestação com base nas expectativas em relação ao filho e nos desejos de maternidade. E por último, o bebê propriamente dito, seria aquele que nasce e com o qual a mãe tem de se adaptar após o nascimento. Para esse autor, o processo da parentalidade, do tornar-se mãe (e também pai) começa pelo bebê imaginário, já que durante a gestação a mãe imagina como será o filho. Quando a criança nasce, a mãe pega no colo não somente o bebê real, mas também o imaginário, que para o autor, é o portador da história transgeracional da mãe e do pai, constituindo-se, assim, um mandato para o destino da criança. Nesse sentido, o nome, o sexo do bebê e demais características tem um papel importante na constituição deste bebê imaginário (Solis-Ponton \& Lebovici, 2004).

Considerando os autores destacados, é importante apontar para a complexidade dos conceitos por eles mencionados, por abrangerem aspectos conscientes e inconscientes do psiquismo parental difíceis de serem investigados separadamente. Dessa forma, torna-se relevante esclarecer que, para este estudo, foi utilizado o termo "bebê imaginado" para designar todos os tipos de bebês que habitam o psiquismo parental durante o período gestacional. Abarcam-se, assim, características conscientes e inconscientes de cada um dos genitores, bem como do casal que eles formam.

Estudos que abordam a temática do bebê imaginado durante a gestação e a constituição da identidade parental são escassos na literatura. Alguns estudos destacam a representação parental com relação ao bebê imaginado embasado em aspectos como o sexo do bebê e a escolha do nome (Piccinini, Ferrari, Levandowski, Lopes, \& Nardi, 2003; Piccinini, Gomes, Moreira, \& Lopes, 2004; Piccinini, Levandowski, Gomes, Lindenmeyer, \& Lopes, 2009), características físicas (Ferrari, Piccinini, \& Lopes, 2007; Piccinini, Ferrari et al., 2003; Piccinini, Levandowski et al., 2009), características psicológicas (Piccinini, Ferrari et al., 2003; Piccinini, Gomes, Moreira et al., 2004; Piccinini, Gomes, Nardi, \& Lopes, 2008; Piccinini, Levandowski et al., 2009), características relativas à saúde do bebê (Piccinini, Gomes, Moreira et al., 2004; Piccinini, Levandowski et al., 2009), bem como aspectos relacionados à interação mãe-bebê (Piccinini, Gomes, Moreira et al., 2004). Estudos também destacam a representação materna em relação ao bebê e em relação a si como mãe durante a gestação (Ammaniti, Tambelli, \& Odorisio, 2012; Benoit, Parker, \& Zeanah, 1997; Dayton, Levendosky, Davidson, \& Bogat, 2010; Huth-Bocks, Levendosky, Theran, \& Bogat, 2004; Huth-Bocks, Theran, Levendosky, \& Bogat, 2011; Pajulo, Helenius, \& Mayes, 2006; Pajulo, Savonlahti, Sourander, Piha, \& Helenius, 2001) como importantes para a relação mãe-bebê e para a constituição da identidade materna que já se iniciaria na gestação e se estenderia após o nascimento do bebê.

O presente estudo parte do pressuposto de que todas as representações do bebê no psiquismo materno e paterno irão influenciar o desenvolvimento do self da criança, ou seja, sua identidade no meio familiar (Golse, 2002), assim como a identidade do homem e da mulher que estão em um momento de transição para a parentalidade. Dessa forma, este estudo teve por objetivo investigar as expectativas parentais em relação ao bebê imaginado e suas influências na constituição da identidade materna, paterna e do bebê durante o terceiro trimestre gestacional.

Interação Psicol., Curitiba, v. 19, n. 3, p. 385-394, set./dez. 2015 


\section{MÉTODO}

\section{Participantes}

Participaram do presente estudo três casais primigestos que se encontravam no terceiro trimestre gestacional no momento inicial do estudo. Os nomes fictícios e dados sobre os casais encontram-se abaixo:

Casal 1) Maria e Rodrigo - Idade de 33 e 40 anos respectivamente. Em união estável há um ano. Em relação à escolaridade, Maria possuía ensino superior incompleto e Rodrigo ensino superior completo. Ambos, no momento inicial do estudo, se encontravam sem emprego fixo. No entanto, Maria estava encerrando os estudos no Curso de Letras e Rodrigo fazia atendimentos domiciliares como fisioterapeuta.

Casal 2) Antonela e Bruno - Idade de 26 e 27 anos respectivamente. Em união estável há sete anos. Em relação à escolaridade, Antonela e Bruno possuíam ensino médio completo e, no momento inicial do estudo, se encontravam empregados.

Casal 3) Cléria e Joaquim - Idade de 23 e 28 anos respectivamente. Em união estável há sete anos. Em relação à escolaridade, Cléria e Joaquim possuíam ensino superior incompleto, sendo que Cléria cursava Psicologia e Joaquim Ciências da Computação. No momento inicial do estudo se encontravam empregados.

Todos os casais eram integrantes de um estudo maior intitulado "Família... cheguei! Expectativas parentais e identidade familiar frente ao nascimento do primeiro filho" (Bossi \& Ardans, 2009) que teve por objetivo geral investigar as expectativas parentais e a mudança de identidade familiar frente ao nascimento do primeiro filho, de maneira longitudinal, do terceiro trimestre gestacional até o terceiro mês de vida do bebê. Os nomes fictícios utilizados no presente estudo foram escolhidos pelos próprios participantes, a fim de manter a confidencialidade dos dados. Vale ressaltar que o número de participantes foi escolhido buscado a investigação aprofundada de cada caso, sem estar interessado na saturação dos dados (Stake, 1994).

\section{Delineamento e procedimentos}

Foi utilizado o delineamento de estudo de caso coletivo (Stake, 1994) que acompanhou os casais no terceiro trimestre gestacional. O convite para a participação na pesquisa foi feito à gestante, sendo que uma participante foi recrutada na Unidade de Saúde em que realizava o pré-natal e, com as demais por meio de indicação. Nesse primeiro contato verificou-se se o casal se adequava aos critérios de inclusão do estudo, tais como: terem idade mínima de 18 anos; estarem no período final da gravidez do primeiro filho para ambos os sujeitos do casal; morarem na mesma residência; autorizarem que as entrevistas fossem realizadas nas suas residências e aceitarem o uso do gravador.

Após esse primeiro contato com as gestantes foi estabelecido um contato telefônico com o objetivo de saber do interesse dos companheiros das mesmas em participar da pesquisa. Com os casais disponíveis para o estudo foi agendado o primeiro encontro para que assinassem o Termo de Consentimento Livre e Esclarecido e fosse realizada a primeira entrevista com o casal. No projeto maior que originou este estudo, foram realizadas quatro entrevistas semiestruturadas com cada casal, sendo duas durante o terceiro trimestre gestacional e duas até o terceiro mês de vida do bebê. Para fins do presente estudo foram analisados os dados referentes à primeira entrevista, que teve como base as seguintes questões: "Vocês já sabem o sexo do bebê?", "Como foi saber que é menino(a)?", "Vocês já escolheram o nome?"; "Como vocês imaginam que o bebê será?". Cada entrevista teve duração média de 30 minutos, sendo que foram gravadas, transcritas e posteriormente analisadas.

Vale ressaltar que este estudo seguiu todas as normas éticas preconizadas pela Resolução 196/96 do Conselho Nacional de Saúde. Dessa forma, o contato com os participantes, bem como a coleta dos dados só teve início após a aprovação no Comitê de Ética em Pesquisa da Universidade Federal de Santa Maria (Proc. $\mathrm{n}^{\circ}$ 0022.0.243.000-09).

\section{RESULTADOS}

A análise dos dados se deu através da análise de conteúdo qualitativa (Bardin, 1977; Laville \& Dionne, 1999), na qual foram elencadas categorias com base no quadro teórico e nos dados empíricos. No projeto maior que originou este estudo foram considerados sete temas de análise, que abordaram as expectativas dos pais e mães em relação ao bebê, a parentalidade antes do nascimento do bebê, os momentos da gravidez, as expectativas e vivências do parto, as vivências do puerpério, a rede de apoio familiar na gestação e 
puerpério e a parentalidade após o nascimento do bebê. Para o presente estudo, considerou-se o tema relacionado às expectativas dos pais e mães em relação ao bebê que foi analisado com base em três categorias, a saber: sexo do bebê, que investigou os sentimentos dos casais frente à revelação do sexo do bebê; escolha do nome, que abordou o processo de escolha do nome do bebê; e, características do bebê imaginado, que investigou as características físicas e psicológicas dos bebês imaginadas pelos casais. A seguir serão apresentados cada caso separadamente a partir das categorias mencionadas, sendo ilustradas através dos relatos dos participantes.

\section{Casal 1: Maria e Rodrigo - à espera do filho Rodrigo}

Sexo do bebê - O bebê gestado pelo casal era um menino, o que foi ao encontro do desejo de Maria, mas não de Rodrigo: "Eu sempre quis uma menina, mas pra mim vem o menino tá bem vindo também". Maria destacou ter ficado "Muito feliz [ao saber o sexo do bebê], foi exatamente aquilo que eu queria". Percebeu-se que mesmo existindo em Rodrigo uma idealização frente ao sexo do bebê, o conhecimento do sexo real do filho não representou uma frustração intolerável. Pode-se dizer que, de alguma forma, Maria continuou com a sua idealização como mãe de um menino. E Rodrigo teve que transformar a sua identidade, já que se idealizou como pai de uma menina. No entanto, como a identidade pressupõe uma mudança constante (Levita, 1965/1977), Rodrigo conseguiu dar conta de transformar essa identidade antes desejada.

Escolha do nome - Quem escolheu o nome do bebê foi Maria que, ao ter seu desejo de ser mãe de um menino realizado, obteve a oportunidade de nomear seu filho. Rodrigo mencionou que o nome do bebê era o mesmo que ele escolheu para representá-lo neste estudo permitindo, de certa forma, perceber a identificação que Rodrigo já possuía com o bebê. Maria explicou que: "Rodrigo é um nome parecido com o meu, assim, por causa da letra $R$ [seu nome verdadeiro inicia com $\mathrm{R}$ ] e eu acho bonito também pelo personagem do Érico Veríssimo ${ }^{2}$ e eu gosto muito de literatu$r a$ ". O casal informou que o nome era composto sendo que Maria escolheu o nome do marido para ser o segundo nome do filho. Pôde-se perceber que a entrevistada colocou, através da nomeação, a expectativa de o filho ter características paternas. No entanto não dispensou que ele também tivesse características mater- nas, demonstrado pela escolha do primeiro nome do filho ser parecido com o seu e também por ser o nome de um personagem literário, já que Maria era estudante do curso de Letras.

Características do bebê imaginado - Maria mencionou características físicas que imaginou que o filho teria "Eu acho que vai ser parecido com o pai dele [...] que vai ser mais..., mais moreno que eu". Já Rodrigo destacou: "Acho que fisicamente nunca idealizei ele não [...] eu quero só que ele seja tranquilo, não que ele seja aquilo que eu não fui, mas que ele seja pelo menos..., pelo menos não, ele sendo um homem de bem pra mim é o suficiente". Nessa passagem, Rodrigo mostrou, de certa forma, um pouco de sua idealização frente aos valores que recebeu de sua própria família, no sentido de ser "um homem de bem". Dessa forma, ele almejou passar ao filho aquilo que recebeu de seus genitores, o que remete ao fato de a família ser o primeiro ambiente social com o qual a criança tem contato constituindo-a enquanto sujeito para o convívio social mais amplo (Ciampa, 1987/ 2001).

Vale ressaltar ainda que, ao longo da entrevista, Rodrigo afirmou: "Tu não pode traçar pro teu filho um perfil que tu vai, de repente, idealiza ele como um procurador do estado e ele quer jogar futebol. O que eu posso fazer? Deixar ele jogar futebol". A relação com o futebol era bastante forte neste casal, já que os entrevistados mencionam almejar colocar o filho em uma escolinha de futebol para que ele jogasse como o pai jogou. Rodrigo declarou não ter sido jogador profissional, mas já via no filho que nem nasceu potencial para isso. $\mathrm{O}$ filho foi percebido como a possibilidade de realização dos sonhos que o pai não conseguiu concretizar (Freud, 1914/1996). Este casal também destacou o desejo de que todos os cuidados dados ao filho hoje, sejam retribuídos por ele quando os pais (o casal entrevistado) estiverem idosos. Cuidar do filho apareceu aqui como uma maneira de garantir o próprio cuidado futuro.

\section{Casal 2: Antonela e Bruno - à espera da filha Rafaella}

Sexo do bebê - O bebê gestado era uma menina, o que foi de encontro ao desejo do casal. Antonela explicou "Ah, é assim [...] é que eu preferia menino né, eu nunca me imaginei mãe de menina [...]. Até porque eu tenho alguns problemas com a minha mãe e eu sempre pensei que se eu tivesse uma menina eu não ia 
saber cuidar, que eu ia ser chata como a minha mãe sabe?". Bruno complementou "É, ela nem queria mais o bebê quando soube que era uma menina" e ele também demonstrou surpresa em ver revelado na ecografia o sexo do bebê. Pode-se mencionar que, de certa forma, Antonela teve receio de vir a repetir com a filha a maternagem que recebeu de sua mãe. Ao desejar um menino seria possível se livrar dos fantasmas que, para ela, assombravam os laços que uniam (ou não uniam) uma mãe e uma filha. $\mathrm{O}$ casal, frente à revelação do sexo do bebê, teve de reconstruir seu desejo e sua identidade já que se viram como pai e mãe de uma menina, situação que nunca haviam sequer imaginado.

Escolha do nome - A escolha do nome, para este casal, "foi uma briga", conforme palavras da própria Antonela. Ela esclareceu que pararam para pensar no nome de menina após os quatro meses e meio de gestação, momento em que souberam do sexo do bebê. Antonela destacou "Ah, assim, é que eu queria Antonela, ele queria outro nome e aí, a gente não se entendia, né?". Bruno complementou "Aí assim, a gente decidiu que não ia ser nem um, nem outro, e decidiu que ia ser Rafaella". Pode-se notar que a escolha de um nome feminino trouxe alguns desentendimentos para o casal, como consequência, de certa forma, da frustração em não conseguir gestar o menino desejado. No entanto, pôde-se verificar como o casal já teve elaborado, em certa medida, os conflitos quanto ao sexo do bebê. Antonela escolheu para representá-la neste estudo o nome que desejou colocar na filha, mostrando algo de uma identificação com a menina. Já Bruno se nomeou com o nome escolhido para o filho menino o que, de certa forma, demonstra algo de um luto que continuava a ser realizado pelo casal em relação ao filho idealizado.

Características do bebê imaginado - Este casal destacou como a filha seria fisicamente através do sonho relatado por Antonela “Ah, assim, até porque eu sonhei com ela sabe, fazia tempo que eu não sonhava e eu sonhei com ela [...] ela era bem..., bem carequinha, bem magrinha, magrinha sabe, e compri$d a$ ". Bruno ressaltou acreditar que a filha seria "bem assim" como a esposa descreveu, no entanto destacou também ter sonhado com a menina e que em seu sonho ela era "mais gordinha". As ecografias auxiliaram a idealização deste casal para com a filha, sendo que
Bruno ressaltou que "Algumas coisas já vi na foto que é dela [da esposa] [...] era o nariz, né?".

É relevante destacar que este casal começou a idealizar a filha quando já estavam na metade do período gestacional, pelo fato de que antes desejavam um menino. No entanto, nos relatos apresentados, pôde-se notar que esse fato não impediu que idealizações da filha ocorressem. Isso possibilitou, de certa forma, a reestruturação da identidade paterna e materna, o que permitiu ao casal se perceber como pai e mãe de uma menina.

\section{Casal 3: Cléria e Joaquim - à espera da filha Manuela}

Sexo do bebê - O bebê gestado pelo casal era uma menina, o que foi ao encontro do desejo de Joaquim. Cléria não mencionou nenhuma idealização frente ao sexo do bebê por esta ser sua primeira gestação. Joaquim declarou que "Querer a gente não queria nenhuma delas", se referindo ao fato de a gestação não ter sido planejada para este momento de suas vidas. $\mathrm{O}$ entrevistado destacou que, ao saber que gestava com sua esposa uma menina, "Eu dei risada porque eu já sabia [...] eu sonhei a noite [que estava com uma menina no colo], aí de manhã me incomodou aquilo e eu disse 'pra mim é guria' e ai eu fui mantendo". Cléria mencionou "No início [da gestação] eu pensei que fosse um menino assim, eu acho que eu torcia um pouquinho, não sei [...] aí depois teve um período em que eu enxergava as meninas, olhava pro cabelinho arrumado e coisa e tal, eu já pensava numa menina". Pode-se mencionar que Cléria efetuou uma idealização para ambos os sexos o que, de certa forma, lhe permitiu se preparar para uma identidade materna independente do sexo do bebê. Já Joaquim, em sua idealização, pareceu se preparar para ser pai de uma menina.

Escolha do nome - A escolha do nome do bebê para este casal foi "trabalhoso" nas palavras de Joaquim. Ele explicou: "Na verdade a gente [...] cada um tinha uma lista de nomes [...] a gente juntou, pegou os melhores e formou outra lista e dentro dessa outra lista a gente foi..., foi..., tirando esse não, esse não, esse não, sobraram dois [nomes]" e Cléria complementou: "É que, se ele [...] colocasse um nome que ele gostasse, mas eu não gostasse, se eu não gostar não é justo, né?". Vê-se que o casal optou por entrar em um consenso em relação ao nome da filha, para que o 
nome escolhido respondesse a expectativas tanto da mãe quanto do pai.

Características do bebê imaginado - $\mathrm{O}$ casal também ressaltou idealizações relativas aos aspectos físicos da filha "Eu imagino que ela vai ser bem branquinha, assim fisicamente falando né, e com os cabelinhos bem escuros, é o que eu imagino" e imediatamente Joaquim ressaltou "Com o nariz dela [mãe] $e$ as orelhas dela também". Ao ser questionado o porquê desse fato, ele explicou "Ah não, [...] quando eu era guri, na escola, apelido qualquer quantia e todos fazendo referência ao nariz e as orelhas. Então [...] imagina uma menina, coisa mais bonitinha com as orelhas e nariz do pai, vai passar a sina que o pai passou. Então não, deixa com o nariz dela e a orelha dela que está bom, ótimo, lindo". Idealizar na filha características maternas remete de certa forma, ao desejo paterno de que a filha não sofresse a sina que o pai passou, compensando, para Joaquim, o sofrimento que vivenciou na infância e que ainda o marcava.

\section{DISCUSSÃO}

Os relatos dos casais em relação ao bebê imaginado estiveram relacionados a aspectos referentes ao sexo do bebê, ao nome escolhido e às características físicas do bebê, indo ao encontro de achados da literatura (Piccinini, Ferrari et al., 2003; Piccinini, Gomes, Nardi et al., 2008; Piccinini, Levandowski et al., 2009). Características psicológicas foram ressaltadas por apenas um participante, não estando presentes nos discursos dos demais. Estudos apontam que as características psicológicas são destacadas pela maior parte dos participantes (Piccinini, Ferrari et al., 2003; Piccinini, Gomes, Moreira et al., 2004; Piccinini, Gomes, Nardi et al., 2008; Piccinini, Levandowski et al., 2009) e mostram-se importantes nas idealizações de pais e mães em relação ao bebê. O que se pode pensar é que os casais do presente estudo foram entrevistados, no máximo, um mês antes do parto. Esse foi um momento em que as idealizações em relação ao bebê já estavam reduzidas em uma tentativa de proteção do filho (e também dos pais e mães) em relação à discrepância entre o bebê imaginado ao longo da gestação e o bebê real que logo ocuparia o espaço construído para ele (e por ele) na família (Brazelton \& Cramer, 1992; Stern, 1997). Nos demais estudos anteriormente destacados, as entrevistas ocorreram em qualquer dos últimos três meses gestacionais. Isso pode ter contri- buído, em certa medida, para diferenças nas representações do filho em cada um desses últimos meses, o que possibilitou que características psicológicas fossem destacadas por grande parte dos participantes.

Pode-se mencionar também que, tanto os pais quanto as mães não apresentaram dificuldades em relatar sobre o bebê imaginado por eles, seja enquanto uma representação do casal, seja através de características idealizadas por cada genitor. Da mesma forma, percebeu-se que não se fizeram presentes diferenças marcantes entre pai e mãe quanto às características mencionadas em relação ao bebê imaginado, o que foi constatado, em certa medida, em outros estudos sobre o tema. Estudo realizado por Piccinini, Levandowski et al. (2009) teve por objetivo investigar as expectativas e sentimentos dos futuros pais (homens) à espera do primeiro filho em relação ao bebê durante o período gestacional. Foram entrevistados 35 futuros pais durante o último trimestre gestacional de suas esposas. Os resultados apontaram que os pais, de modo geral, expressaram com facilidade as representações em relação ao bebê, de modo que já haviam estruturado uma imagem mental do filho. Tal imagem mental estava relacionada a sentimentos e expectativas quanto ao sexo do bebê, ao seu nome, às características físicas e psicológicas, e à saúde do bebê. Outro estudo realizado por Piccinini, Gomes, Moreira et al. (2004) com objetivo semelhante ao estudo citado, no entanto investigando os sentimentos e expectativas de gestantes primigestas, entrevistou 39 mulheres no último trimestre gestacional. A análise de conteúdo apontou que, já na gestação, as mães atribuíam uma identidade ao bebê através dos seus sentimentos e expectativas. Estes estavam relacionados às características já citadas no estudo anterior (sexo, nome, características psicológicas e saúde do bebê) bem como pela interação estabelecida entre mãe-bebê no período gestacional.

No presente estudo, destaca-se que o sexo do bebê apareceu, em certa medida, como formador da identidade dos pais e mães, sendo que o mesmo não vir com o sexo desejado colocou a emergência de uma mudança a ser processada no casal (ou em um dos sujeitos da dupla). Ressalta-se, dessa forma, que a revelação do sexo do bebê foi profilática (Szejer \& Stewart, 1997/2002), já que os participantes puderam elaborar suas decepções fazendo uma reconstrução de desejos. Isso permitiu, em certa medida, a mudança para uma identidade materna ou paterna de acordo com o sexo real do bebê. Apenas um dos participantes (de um dos 
casais) mostrou ter se preparado para uma identidade materna independente do sexo do bebê.

Aspectos relacionados ao sexo do bebê, bem como demais características físicas, permitem pensar na influência do exame ultrassonográfico na construção do bebê imaginado. Caron, Fonseca e Kompinsky (2000) destacaram que a ecografia é um "nascimento antecipado", o que proporciona uma intensa sobrecarga emocional nas mães e pais. As autoras mencionaram que, a partir da utilização do exame de ultrassonagrafia, a confrontação entre o bebê imaginário e o bebê real passou a se dar bem antes do nascimento do filho. Tal fato tende a interferir, de diferentes maneiras, na representação do bebê imaginário de cada mãe e pai. Da mesma forma, o estudo de Gomes e Piccinini (2005), a partir da revisão de literatura realizada, destacou que a antecipação do sexo do bebê, de características físicas, assim como do diagnóstico de anormalidades fetais, permitem pensar que o exame ultrassonográfico pode afetar, de diferentes maneiras, a relação materno fetal e ter grande potencial para afetar a relação posterior pais-bebê. Na mesma direção, o estudo realizado por Grigoletti (2005) teve por objetivo investigar a influência da ultrassonografia na representação psíquica que a mãe tinha do filho durante a gestação. Para isso, participaram do estudo 10 gestantes, primíparas e multíparas de diferentes níveis socioeconômicos. Foram realizadas entrevistas individuais e em grupo, bem como observações durante a ultrassonografia. Os resultados apontaram que o exame ultrassonográfico possibilitou às mães uma aproximação com um filho mais real e menos idealizado, o que permitiu a elaboração afetiva das próprias gestantes em relação ao seu filho. Tal aspecto corrobora, em certa medida, achados do presente estudo, já que as mães e pais elaboraram sua identidade materna e paterna, o que permitiu ir ao encontro do sexo real do filho, e não mais do idealizado.

Saber o sexo do bebê implicou em ter com maior exatidão sua identidade, permitindo a ele já ser nomeado (Szejer \& Stewart, 1997/2002). Pôde-se perceber que a nomeação do bebê em gestação já contribuía para os casais, de certa forma, se prepararem para a nova identidade que se estruturava. No sentido de que ao nomearem o filho os pais e mães já viam sua própria identidade sendo transformada, da mesma forma que colocavam uma característica identitária da criança, lhe permitindo ser sujeito na família. Vale lembrar aqui o fato de a identidade ser constituída, principal- mente, através da linguagem e de que, sem nomeação, dificilmente uma identidade será constituída (Ciampa, 1987/2001; Silva, 2000/2005). Essa nomeação se dá a partir de atribuições de características físicas e psicológicas em relação à criança, assim como através da escolha do seu nome. O nome próprio é uma importante forma de representação da identidade. Isso porque ao mesmo tempo em que inclui alguém em uma família, a partir dos atributos do sobrenome, também passa a diferenciá-lo de todos os demais integrantes da família pelos atributos do prenome que porta a singularidade dos sujeitos (Martins, 1984/1991; Ciampa, 1987/2001; Szejer \& Stewart, 1997/2002). O nome tem toda essa força em relação à constituição da identidade por sua escolha estar pautada em expectativas paternas e maternas que se estruturam de forma inconsciente (Martins, 1984/1991). Isso permite aos pais e mães uma relação com o bebê antes mesmo de ele nascer, e possibilita, assim, que uma identidade já se estruture.

No presente estudo, o nome, diferentemente da forma como cada casal o escolheu, trouxe algo de ambos os genitores. Isso pôde ser percebido no discurso dos casais ao destacarem que os nomes teriam que agradar a ambos os genitores, seja para compensar o fato de o bebê não vir com o sexo desejado por um ou ambos os pais, seja por ser injusto o nome agradar a apenas um deles. A escolha do nome exige todo esse investimento psíquico devido a sua importância na constituição da identidade, tanto dos pais e mães quanto dos filhos. $\mathrm{O}$ nome se estrutura a partir de expectativas maternas e paternas que se dão de forma inconsciente e, por isso mesmo, segundo Martins (1984/1991), demonstra algo que vem tanto de quem nomeia como de quem é nomeado. Estudos destacam que o nome escolhido para o bebê é baseado, na sua grande maioria, no fato de os pais e mães simplesmente simpatizarem com o nome (Piccinini, Ferrari et al., 2003; Piccinini, Gomes, Moreira et al., 2004), terem se inspirado em cantores e personagens de novela (no presente estudo uma escolha foi feita a partir da inspiração em um personagem literário), escolherem o nome de parentes queridos (no presente estudo o segundo nome de um dos bebês é o nome paterno), nomes de acordo com a devoção religiosa, como nomes de anjos e santos (Piccinini, Ferrari et al., 2003), características do próprio nome como seu significado e pelo o que o nome lembrava ou remetia aos 
pais e mães (Piccinini, Gomes, Moreira et al., 2004; Piccinini, Levandowski et al., 2009).

Outro aspecto importante de ser ressaltado é que três sujeitos (dos seis entrevistados), justamente os que sofreram decepções frente ao sexo do bebê, escolheram como nome fictício, para este estudo, o nome do filho ou o nome que desejavam colocar nele, o que demonstra, de certa forma, uma identificação com a criança. Levita (1965/1977) entende por "elementos identificatórios" todos os fatores que podem se transformar em identidade. Se nomear com o nome do filho (ou o desejado para ele) serviu, em certa medida, como elemento identificatório que se transformou em identidade materna e paterna nos sujeitos que sofreram decepções relativas ao sexo do bebê.

A respeito das demais características do bebê imaginado, apenas um dos participantes não mencionou idealizações relativas a características físicas do filho. Porém, foi justamente esse entrevistado que trouxe mais idealizações vinculadas ao desejo de que o bebê pudesse realizar os sonhos que ele próprio não conseguiu concretizar. Dessa forma, o investimento na criança foi grandemente narcísico, já que os genitores almejavam estruturar a identidade da criança de forma a satisfazer seus próprios anseios (Freud, 1914/1996). Esse participante também foi o único que trouxe aspectos referentes às características psicológicas da criança, no sentido de ser "tranquilo" e um "homem de bem". Outro participante idealizou na filha características físicas que a livravam de ter que passar pela "sina" suportada pelo pai (o próprio participante) em virtude da sua aparência. Outro casal destacou que, através da ultrassonografia, conseguiu visualizar características físicas maternas na filha. Estudo realizado por Piccinini, Levandowski et al. (2009) com pais (homens) à espera do primeiro filho, constatou que as expectativas quanto às características físicas do bebê estavam relacionadas às próprias características dos genitores, no sentido de desejar que seja parecido ou diferente do pai ou da mãe. Já estudo realizado com 39 gestantes primíparas no terceiro trimestre gestacional (Piccinini, Gomes, Moreira et al., 2004) destacou que as mesmas não apresentaram expectativas quanto a características físicas do bebê, e sim quanto a características psicológicas. Tal fato vai de encontro com os resultados do presente estudo, já que as mulheres (e homens) verbalizaram sobre as características físicas do bebê imaginado, enquanto nenhuma característica psicológica foi ressaltada no discurso das gestantes, sendo destacada por apenas um dos homens entrevistado, como já mencionado.

Com base nos resultados apresentados, pôde-se constatar, de maneira geral, que o bebê já existia na fala dos genitores no momento da gestação, não sendo qualquer bebê, mas este bebê nomeado pelos casais em questão. Isso faz pensar que, nos participantes do presente estudo, já se apresentavam, de certa forma, as identidades materna e paterna, o que colocava que eles não seriam futuros pais e mães, mas já seriam pais e mães da criança imaginada, ao dispensarem um espaço psíquico dedicado ao bebê (Piccinini, Gomes, Nardi et al., 2008). Isso permitiu que as idealizações (ou a decepção frente a elas como no caso do sexo do bebê) também colocassem a identidade em novas elaborações e reconstruções.

O presente estudo permite pensar o quão complexo é a constituição da parentalidade e da identidade no ambiente familiar. Ainda mais quando se investiga tal fenômeno com base em um conceito que envolve aspectos conscientes e inconscientes, como o de bebê imaginado, difícil de ser captado através de entrevistas e em um único momento de coleta. Sugere-se, para futuros estudos, o acompanhamento dos casais durante todo o período gestacional, o que permitirá aprimorar o conhecimento acerca das mudanças de expectativa em relação ao bebê ao longo dos trimestres gestacionais.

Da mesma forma, o acompanhamento das famílias ao longo dos primeiros anos de vida dos filhos possibilitaria acessar os diferentes recursos psicológicos utilizados pelos pais e mães para se adequar à discrepância entre o bebê imaginado e o real. Isso poderia auxiliar, inclusive, no trabalho clínico com mães, pais e bebês quando a elaboração em relação ao bebê imaginado não se dá de forma satisfatória. Apesar dessas possíveis limitações, os resultados do presente estudo, em conjunto, mostram o quanto as idealizações em relação ao bebê são importantes recursos psíquicos para a constituição das identidades materna, paterna e do bebê.

\section{REFERÊNCIAS}

Ammaniti, M., Tambelli, R., \& Odorisio, F. (2012). Exploring maternal representations during pregnancy in normal and at-risk samples: The use of the interview of maternal representations during pregnancy. Infant Mental Health Journal, 34(1), 1-10. 
Bardin, L. (1977). Análise de Conteúdo. Lisboa: Edições 70 LDA.

Benoit, D., Parker, K. C. H., \& Zeanah, C. H. (1997). Mothers' representations of their infants assessed prenatally: Stability and association with infants' attachment classifications. Journal Child Psychology and Psychiatry, 38(3), 307-313.

Bossi, T. J., \& Ardans, O. (2009). Família...cheguei! Expectativas parentais e identidade familiar frente ao nascimento do primeiro filho. Projeto de pesquisa não publicado. Universidade Federal de Santa Maria, Santa Maria.

Brazelton, T. B., \& Cramer, B. G. (1992). As primeiras relações (M. B. Cipolla, Trans.). São Paulo: Martins Fontes.

Caron, N. A., Fonseca, M. M. C., \& Kompinsky, E. (2000). Aplicação da observação na ultrassonografia obstétrica. Em N. A. Caron (Org.), A relação pais-bebê: Da observação à clínica (pp. 178-206). São Paulo: Casa do Psicólogo.

Ciampa, A. da C. (2001) A estória do Severino e a história da Severina. São Paulo: Brasiliense. (Trabalho original publicado em 1987).

Conselho Nacional de Saúde (1996). Resolução $N^{\circ} 196$ de 10 de outubro de 1996. Retirado de http://conselho.sau de.gov.br/resolucoes/reso_96.htm

Dayton, C. J., Levendosky, A. A., Davidson, W. S., \& Bogat, G. A. (2010). The child as held in the mind of the mother: The influence of prenatal maternal representations on parenting behaviors. Infant Mental Health Journal, 31(2), 220-241.

Ferrari, A.G., Piccinini, C.A., \& Lopes, R.S. (2007). O bebê imaginado na gestação: Aspectos teóricos e empíricos. Psicologia em Estudo, 12(2), 305-313.

Freud, S. (1996). Sobre o narcisismo: uma introdução (J. Salomão. Trans.). Edição Standard Brasileira das Obras psicológicas completas de Sigmund Freud. (V.14, pp. 77-108). Rio de Janeiro: Imago. (Trabalho original publicado em 1914).

Golse, B. (2002). O que temos aprendido com os bebês. Em Filho, L. C.; Corrêa, M. E. G., \& França, P.S. (coord.), Novos olhares sobre a gestação e a criança até os 3 anos (pp. 116-134). Brasília: Editora L.G.E.

Gomes, A. G., \& Piccinini, C. A. (2005). A ultra-sonografia obstétrica e a relação materno-fetal em situações de normalidade e anormalidade fetal. Estudos de Psicologia, 22(4), 381-393.

Grigoletti, L. V. S. (2005). A influência da ultrassonografia na representação do filho imaginário-filho real. Psico, $36(2), 149-157$.
Huth-Bocks, A. C., Levendosky, A. A., Theran, S. A., \& Bogat, G. A. (2004). The impact of domestic violence on mothers' prenatal representations of their infants. Infant Mental Health Journal, 25(2), 79-98.

Huth-Bocks, A. C., Theran, S. A., Levendosky, A. A., \& Bogat, G. A. (2011). A social-contextual understanding of concordance and discordance between maternal prenatal representations of the infant and infant-mother attachment. Infant Mental Health Journal, 32(4), 405-426.

Laville, C. \& Dionne, J. (1999). A construção do saber: manual de metodologia da pesquisa em ciências humanas (H. Monteiro \& F. Settineri, Trans.). Porto Alegre: Artmed.

Lebovici, S. (1987). O bebê, a mãe e o psicanalista (F. Vidal, Trans). Porto Alegre: Artes Médicas.

Levita, D.J. de. (1977) El concepto de identidad (M. Mizraji, Trans.). Buenos Aires: Marymar. (Trabalho original publicado em 1965).

Martins, F. (1991). O nome próprio: da gênese do Eu ao reconhecimento do outro. Brasília, DF: Editora da Universidade de Brasília. (Trabalho original publicado em 1984).

Pajulo, M., Helenius, H., \& Mayes, L. (2006). Prenatal views of baby and parenthood: Association with sociodemographic and pregnancy factors. Infant Mental Health Journal, 27(3), 229-250.

Pajulo, M., Savonlahti, E., Sourander, A., Piha, J., \& Helenius, H. (2001). Prenatal maternal representations: Mothers at psychosocial risk. Infant Mental Health Journal, 22(5), 529-544.

Piccinini, C. A., Ferrari, A. G., Levandowski, D. C., \& Lopes, R. S., \& Nardi, T. C. (2003). O bebê imaginário e as expectativas quanto ao futuro do filho em gestantes adolescentes e adultas. Interações, VIII(16), 81-108.

Piccinini, C. A., Gomes, A. G., Moreira, L. E., \& Lopes, R. S. (2004). Expectativas e sentimentos da gestante em relação ao seu bebê. Psicologia: Teoria e Pesquisa, 20(3), 223-232.

Piccinini, C. A.; Gomes, A. G.; Nardi, T. de, \& Lopes, R. S. (2008). Gestação e constituição da maternidade. Psicologia em Estudo, 13(1), 63-72.

Piccinini, C. A., Levandowski, D. C., Gomes, A. G., Lindenmeyer, D., \& Lopes, R.S. (2009). Expectativas e sentimentos de pais em relação ao bebê durante a gestação. Estudos de Psicologia, 26(3), 373-382.

Silva, T. T. da. (2005). A produção social da identidade e da diferença. Em T. T. da Silva; S. Hall; K. Woodward (Orgs.), Identidade e diferença: a perspectiva dos estudos culturais (pp. 73-98). Petrópolis, RJ: Vozes. (Trabalho original publicado em 2000). 
Solis-Ponton, L., \& Lebovici, S. (2004). Diálogo Leticia Solis-Ponton e Serge Lebovici (T. S. V. Rebelo, trad.). Em L. Solis-Ponton (Org.), Ser pai, ser mãe: Parentalidade: Um desafio para o terceiro milênio (pp. 21-27). São Paulo: Casa do Psicólogo.

Stake, R. E. (1994). Case studies. Em N. K. Denzin \& Y. S. Lincoln (Eds.), Handbook of qualitative research. New York: Sage Publications.

Stern, D. N. (1997). A constelação da maternidade: O panorama da psicoterapia pais-bebê (M. A. Veronese, trad.). Porto Alegre: Artes Médicas.
Szejer, M., \& Stewart, R. (2002). Nove meses na vida da mulher: uma aproximação psicanalítica da gravidez $e$ do nascimento (M. N. B. Benetti, trad.). São Paulo: Casa do Psicólogo. (Trabalho original publicado em 1997).

\section{Notas:}

1 No presente estudo, o termo "pais" foi utilizado como plural de "pai".

2 O personagem é Capitão Rodrigo, da trilogia "O tempo e o vento". 